\title{
SIMPANAN KARBON SEBAGAI SALAH SATU INDIKATOR KESEHATAN HUTAN PADA HUTAN RAKYAT \\ (Studi Kasus di Hutan Rakyat Kelurahan Pinang Jaya, Kecamatan Kemiling, Kota Bandar Lampung, Provinsi Lampung)
}

\author{
Carbon Stock as One of Forest Health Indicators at Community Forest \\ (Case Study in Community Forest at Pinang Jaya Village, Kemiling Sub-District, Bandar Lampung \\ City, Lampung Province ) \\ Vita Arianasari, Rahmat Safe'i, Arief Darmawan, Hari Kaskoyo \\ Jurusan Kehutanan, Fakultas Pertanian, Universitas Lampung \\ JIn. Prof. Dr. Soemantri Brojonegoro No. 1 Gedung Meneng, Bandar Lampung \\ *Email : vitaariana120@gmail.com
}

Diterima: 21/10/2020, Direvisi: 19/11/2020, Disetujui: 22/11/2020

\begin{abstract}
Global climate change and forest health are currently two things that need to be studied more deeply. Forests store carbon, including in the community forests. A healthy forest can perform its function properly including as a carbon sinker as well as a carbon repository. This study aims to analyze carbon storage as an indicator of forest health in community forests in Pinang Jaya Village. The data were collected by using cluster plots based on the method of Forest Health Monitoring (FHM), totaling 15 units. The measurement method used is destructive and non-destructive. The result showed that the average carbon storage in community forests in Pinang Jaya Village is $54.59 \mathrm{tC} / \mathrm{ha}$. The largest contribution to carbon storage was $A G B$ with a percentage of $95.71 \%$, followed by necromass at $4.23 \%$, and $0.05 \%$ litter and understorey. Based on the results of the analysis, carbon storage can perform as an indicator of forest health in the community forests of Pinang Jaya Village with the bad, medium, and good categories. The plot clusters are in the Good category (70.61 tC/ha - 83.66 tC/ha), namely cluster plots 13, Moderate categories (57.55 tC/ha - 70.60 tC/ha), namely cluster plots 4 and 14, and the Bad category (44.49 tC/ha - $57.54 \mathrm{tC} / \mathrm{ha})$, namely cluster plots $1-3,5-12.15$, with the percentage of each category of $7 \%, 13 \%$, and $80 \%$.
\end{abstract}

Keyword: carbon storage, climate change, cluster plot, forest health indicators.

\section{ABSTRAK}

Perubahan iklim global dan kesehatan hutan saat ini menjadi dua hal yang penting untuk dikaji lebih dalam. Hutan berfungsi sebagai penyimpan karbon, termasuk pada hutan rakyat. Hutan yang sehat dapat menjalankan fungsinya dengan baik sebagai penyerap dan penyimpan karbon dari udara. Penelitian ini bertujuan untuk menganalisis simpanan karbon sebagai salah satu indikator kesehatan hutan pada hutan rakyat di Kelurahan Pinang Jaya. Pengumpulan data dilakukan dengan klaster plot berdasarkan metode Forest Health Monitoring (FHM) yang berjumlah 15 buah. Metode pengukuran yang dipakai adalah destruktif dan non-destruktif. Hasil penelitian menunjukan rata-rata simpanan karbon pada hutan rakyat di Kelurahan Pinang Jaya 
adalah 54,59 tC/ha. Sumbangsih simpanan karbon terbesar adalah AGB dengan persentase $95,71 \%$, diikuti nekromasa sebesar $4,23 \%$, serta serasah dan tumbuhan bawah $0,05 \%$. Berdasarkan hasil analisis, karbon dapat menjadi indikator kesehatan hutan pada hutan rakyat Kelurahan Pinang Jaya dengan kategori buruk, sedang, dan baik. Klaster plot yang termasuk kategori Baik $(70,61 \mathrm{tC} / \mathrm{ha}-83,66 \mathrm{tC} / \mathrm{ha})$ yaitu klaster plot 13 , kategori Sedang $(57,55 \mathrm{tC} / \mathrm{ha}-$ $70,60 \mathrm{tC} / \mathrm{ha})$ yaitu klaster plot 4 dan 14, dan kategori Buruk (44,49 tC/ha $-57,54 \mathrm{tC} / \mathrm{ha})$ yaitu klaster plot 1-3, 5-12,15, dengan persentase masing-masing kategori sebesar $7 \%$, 13\%, dan $80 \%$.

Kata kunci: indikator kesehatan hutan, klaster plot, perubahan iklim, simpanan karbon.

\section{PENDAHULUAN}

Perubahan iklim dan kesehatan hutan menjadi dua hal penting yang saling berkaitan. Mitigasi perubahan iklim global telah banyak dirancang dan menjadi hal yang penting untuk dipertimbangkan dalam berbagai forum dan keputusan, sedangkan kesehatan hutan menjadi kriteria pengelolaan hutan yang lestari yang dapat menjadi salah satu mitigasi perubahan iklim. Menurut Safe'i et al. (2015), kriteria dan indikator kelestarian hutan telah banyak diformulasikan oleh masing-masing lembaga pemerintah maupun non pemerintah dengan cakupan nasional, regional, dan internasional. Secara umum, kondisi hutan yang baik dapat mengemban fungsi ekologisnya dengan baik, salah satunya sebagai penyimpan karbon. Pengetahuan tentang simpanan karbon memungkinkan untuk mengetahui fungsi hutan dalam mendukung penurunan gas rumah kaca (GRK) dalam kaitannya dengan perubahan iklim global (Suharjo dan Wardhana, 2011). Hutan yang sehat secara aktif dapat menyimpan karbon melalui pertumbuhan hutan, menahan patogen dan wabah serta dapat memulihkan diri dari berbagai kerusakan (EPA, 2013).

Penyimpanan karbon oleh hutan telah mendapat perhatian yang terus meningkat dalam beberapa tahun terakhir karena kesadaran bahwa hutan memainkan peran penting dalam menstabilkan GRK. Perhatian yang sama juga diberikan pada berkembangnya hutan rakyat di Indonesia. Hutan rakyat mempunyai potensi yang besar dan dengan kondisi hutan yang luas serta kondisi vegetasi yang baik akan menghasilkan akumulasi penyerapan $\mathrm{CO}_{2}$ yang besar (Ristiara et al., 2017) karena penyusun tegakannya mayoritas memiliki pola tanam campuran atau agroforestri. Pola tanam agroforestri adalah pola tanam dengan mengkombinasikan tanaman kehutanan dengan tanaman pertanian atau perkebunan pada satu areal (Rizki et al., 2016), sehingga memungkinkan simpanan karbon yang ada di hutan rakyat cenderung besar.

Hutan dikatakan sehat apabila hutan tersebut masih dapat memenuhi fungsinya. Fungsi hutan yang cukup menjadi sorotan adalah sebagai penyimpan karbon dan akan maksimal jika kondisi hutannya baik. Kesehatan hutan dikategorikan menjadi beberapa jenis dan berdasarkan beberapa indikator penilaian. Safe'i et al. (2015) menyatakan bahwa pemantauan kesehatan hutan dapat dilakukan dengan menggunakan beberapa indikator, yang terdiri dari vitalitas, produktivitas, biodiversitas dan kualitas tapak.

Indikator kesehatan hutan pada kenyataanya dapat berkembang. Seperti pada penelitian Lestari et al. (2019), menyatakan bahwa indikator kesehatan hutan yang diukur berbeda-beda bergantung pada upaya pengelolaan hutan yang ingin dicapai. Penelitian ini penting dilakukan kerena data mengenai simpanan karbon sebagai indikator kesehatan hutan pada hutan rakyat belum tersedia. Penelitian ini bertujuan menganalisis simpanan karbon 
Jurnal Belantara Vol. 4, No 2, Agustus 2021 (164-175)

sebagai indikator kesehatan hutan pada hutan rakyat di Kelurahan Pinang Jaya, Kecamatan Kemiling, Kota Bandar Lampung, Provinsi Lampung.

\section{METODE}

\section{Alat dan Bahan}

Alat dan bahan yang digunakan dalam penelitian yaitu tali rafia, kompas, kamera digital, alat tulis, phiband, timbangan, GPS (global positioning system), dan PC (personal computer).

\section{Lokasi Penelitian}

Penelitian ini dilakukan pada hutan rakyat di Kelurahan Pinang Jaya Kecamatan Kemiling, Kota Bandar Lampung, Provinsi Lampung yang memiliki luas 78,01 ha.

\section{Plot Pengukuran}

Pengambilan data penelitian dilakukan secara sampling dengan intensitas sampling sebesar 7,5 \% (5,85 ha) dari total luas hutan rakyat pada wilayah tersebut. Menurut Umroni (2012) intensitas sampling ditentukan berdasarkan tingkat ketelitian, biaya, serta kemampuan inventor, sedangkan berdasarkan Departemen Kehutanan (2013), mengacu pada Inventarisasi Hutan Nasional (IHN), intensitas sampling yang banyak digunakan yaitu sebesar $1 \%$, oleh karena itu, maka penggunaan intensitas sampling sebesar 7,5 \% dapat diterima karena semakin besar intensitas sampling yang digunakan dalam sebuah penelitian maka akan memperbesar tingkat ketelitiannya, dan pernyataan ini sejalan dengan penelitian Umroni (2012) bahwa secara normatif nilai intensitas sampling yang tinggi akan sebanding dengan tingkat akurasinya.

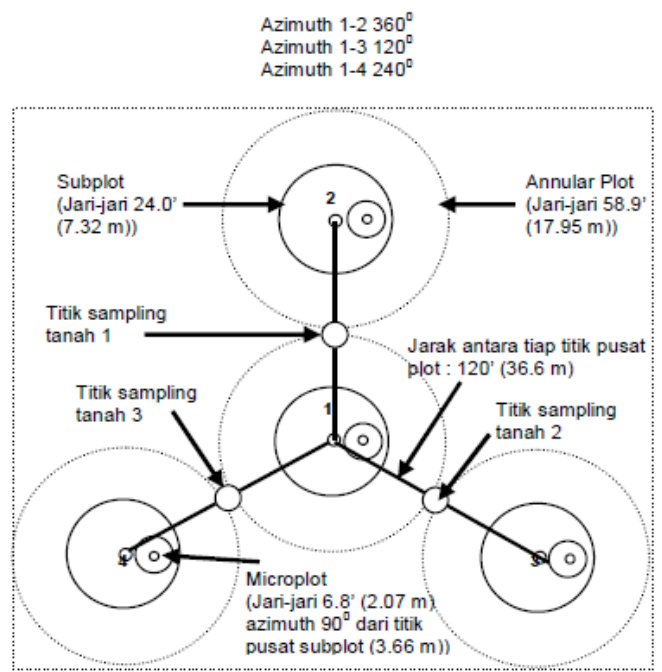

Gambar 1. Desain klaster plot (USDA-FS, 1999).

Figure 1. Design of plot cluster (USDA-FS, 1999).

FHM diadopsi oleh SEAMEO BIOTROP yang dirintis oleh EPA-USDA-FS untuk memantau kelestarian hutan hujan tropis Indonesia (ITTO \& SEAMEO BIOTROP, 2001) 
dengan menggunakan jenis plot contoh. Plot contoh yang diambil menggunakan jenis klaster plot yang berasal dari metode FHM tersebut (USDA-FS, 1999) yang terdapat pada Gambar 1 dan terdiri dari annular plot, subplot, dan mikroplot. Menurut ITTO \& SEAMEO BIOTROP (2001) FHM ini pertama kali dikembangkan di A.S. pada tahun 1991. FHM adalah pendekatan ekologis untuk mengevaluasi ekosistem hutan terhadap kondisi, perubahan, tren, agen penyebab dan mekanisme untuk memantau kondisi dan perubahan hutan ekosistem.

Klaster plot dibuat sesuai dengan penggunaan pada tiga gudang karbon. Klaster plot yang dibuat yaitu sebanyak 15 buah sesuai dengan intensitas sampling yang digunakan (7,5\%) dan peletakan klaster plot dilakukan dengan random sederhana menggunakan Ms. Excel sehingga tersebar secara acak pada grid (garis khayal berbentuk persegi) yang telah dibuat di atas hutan rakyat. Persebaran klaster plot dapat dilihat pada Gambar 2.

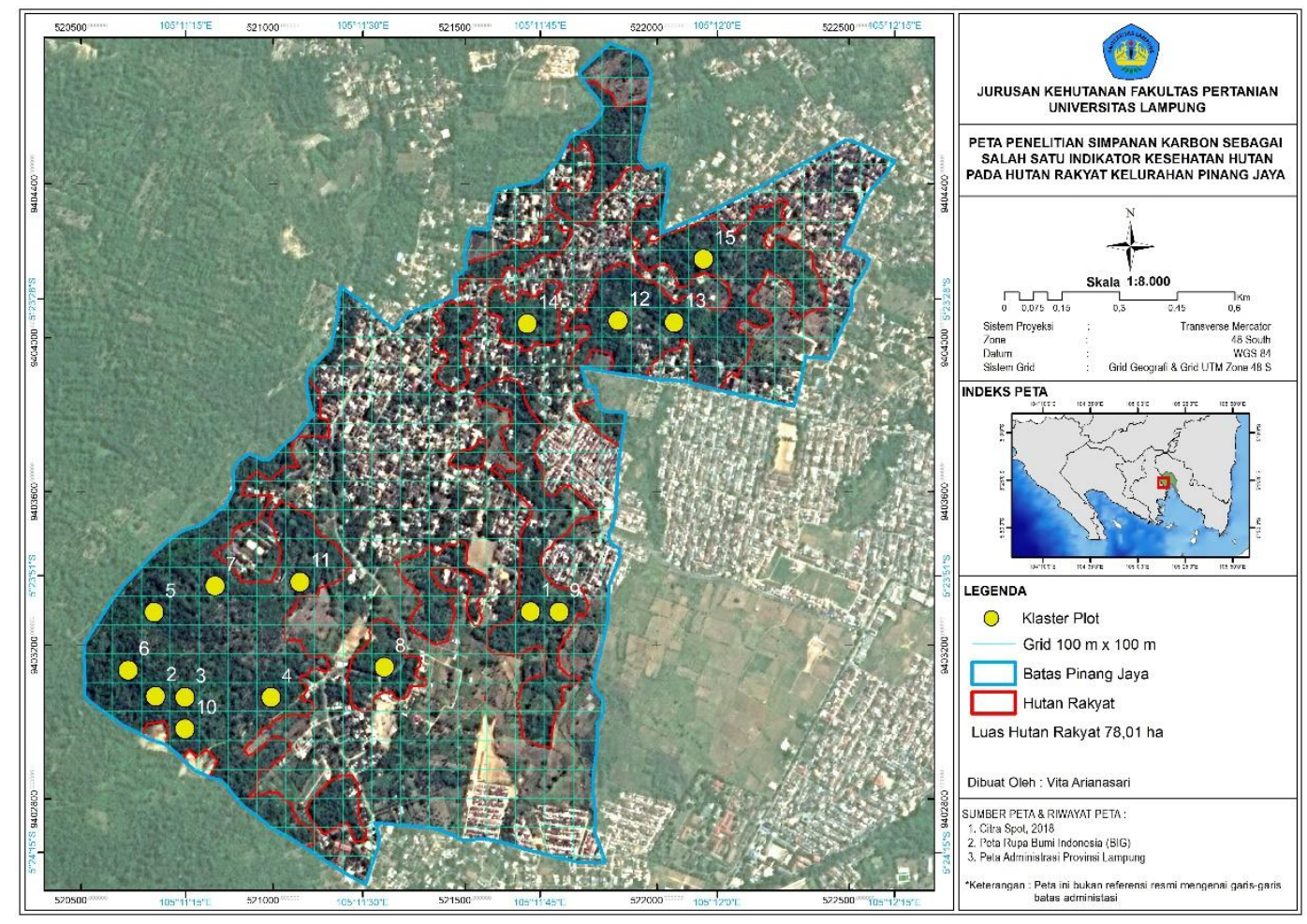

Gambar 2. Persebaran Klaster Plot

Figure 2. Distribution of Plot Cluster

\section{Perhitungan dan Analisis Data}

Gudang karbon (carbon pool) yang diukur meliputi AGB (Above Ground Biomass); nekromasa; serasah, dan tumbuhan bawah. Pendugaan nilai AGB dan nekromasa menggunakan satu persamaan allometrik terpilih, namun pada nekromasa, untuk mengetahui nilai per-individunya, faktor koreksi harus digunakan pada tanaman mati. Faktor koreksi yang digunakan yakni menurut Manuri et al. (2011) meliputi 0,7; 0,8; dan 0,9. Penggunaan rumus allometrik terpilih yakni yang sesuai dengan iklim tropis di Indonesia yang dikembangkan oleh Chave et al. (2005):

$$
B=\rho \times \exp \left(-1.499+2.148 \ln (\mathrm{D})+0,207(\ln (\mathrm{D}))^{2}-0.0281(\ln (\mathrm{D}))^{3}\right.
$$


Keterangan:

B = biomasa total $(\mathrm{kg})$;

$\mathrm{D}=$ diameter setinggi dada $(\mathrm{m})$;

$\rho=$ kerapatan jenis kayu $\left(\mathrm{gr}_{\mathrm{cm}}{ }^{3}\right)$

Pendugaan biomasa pada serasah dan tumbuhan bawah diperoleh dengan menggunakan rumus Biomass Expansion Factor yang digunakan oleh Brown (1997) :

Keterangan :

$$
\text { Total BK }=\frac{\text { BK sub contoh }(\mathrm{g})}{\mathrm{BB} \text { sub contoh }(\mathrm{g})} \times \text { total BB }
$$

$\mathrm{BB}=$ berat basah $(\mathrm{g})$;

$\mathrm{BK}=$ berat kering

Potensi karbon dapat diduga melalui besar biomasa yang telah diperoleh dari vegetasi, nekromasa, serasah, dan tumbuhan bawah dengan mengkonversi 0,47 dari biomasa maupun nekromasanya (BSN, 2011):

Keterangan :

C $=$ karbon $(\mathrm{kg})$;

$\mathrm{B}=$ biomasa tumbuhan $(\mathrm{kg})$;

$0,47=$ faktor konversi untuk pendugaan karbon.

Kemudian, kesehatan hutan pada hutan rakyat Kelurahan Pinang Jaya dikategorikan ke dalam 3 kategori, yaitu Baik, Sedang, dan Buruk. Kategori ini diperoleh dengan menentukan nilai ambang simpanan karbon hutan berdasarkan nilai maksimum dan minimum data penelitian (Lestari, 2017). Nilai ambang simpanan karbon hutan pada penelitian ini diperoleh berdasarkan interval kelas. Menurut Djumanta dan Susanti (2008), interval kelas adalah selisih antara data terbesar dengan data terkecil dibagi dengan banyaknya kelas yang dapat dirumuskan:

Keterangan :

$$
\mathrm{p}=\mathrm{R} / \mathrm{k}
$$

$\mathrm{p}=$ panjang kelas

$\mathrm{R}$ = rentang

$\mathrm{k}$ = banyaknya kelas

\section{HASIL DAN PEMBAHASAN}

\section{Vegetasi Hutan Rakyat Kelurahan Pinang Jaya}

Pola agroforestri yang diterapkan oleh petani di hutan rakyat Kelurahan Pinang Jaya menjadikan keanekaragaman vegetasinya cukup tinggi sehingga bisa berkorelasi positif terhadap simpanan karbonnya dan didukung oleh kondisi tanaman yang baik. Jenis vegetasi yang diinventarisasi beserta kelimpahannya yang ada di hutan rakyat Kelurahan Pinang Jaya terdapat pada Tabel 1. 
Simpanan Karbon Sebagai Salah Satu Indikator Kesehatan... (Arianasari, dkk)

Tabel 1. Jenis Tanaman dan Kelimpahannya

Table 1. Species and Individual Tree Quantity

\begin{tabular}{lllc}
\hline No & Nama spesies & Nama ilmiah & Jumlah individu \\
\hline 1 & Akasia daun kecil & Acacia mangium & 26 \\
2 & Akasia daun lebar & Acacia auriculiformis & 3 \\
3 & Alpukat & Persea Americana & 13 \\
4 & Bayur & Pterospermum javanicum & 59 \\
5 & Cempaka & Michelia champaca & 57 \\
6 & Cengkeh & Syzygium aromaticum & 8 \\
7 & Durian & Durio zibethinus & 40 \\
8 & Flamboyan & Dendropanax regia & 2 \\
9 & Jabon & Anthocephalus cadamba & 6 \\
10 & Jambu biji & Psidium guajava & 6 \\
11 & Jati & Tectona grandis & 116 \\
12 & Jati putih & Gmelina arborea & 2 \\
13 & Jengkol & Archidendron jiringa & 15 \\
14 & Kakao & Theobroma cacao & 356 \\
15 & Karet & Hevea brasiliensis & 74 \\
16 & Kelapa & Cocos nucifera & 38 \\
17 & Ketapang & Terminalia catappa & 5 \\
18 & Kopi & Coffea sp. & 25 \\
19 & Lamtoro & Leucaena leucocephala & 11 \\
20 & Mahoni & Swietenia mahagoni & 26 \\
21 & Mangga & Mangifera indica & 39 \\
22 & Medang & Blumeodendron kurzii & 5 \\
23 & Melinjo & Gnetum gnemon & 122 \\
24 & Nangka & Artocarpus heterophyllus & 16 \\
25 & Petai & Parkia speciosa & 102 \\
26 & Rambutan & Nephelium lappaceum & 7 \\
27 & Randu & Ceiba pentandra & 5 \\
28 & Sengon Buto & Albizia chinensis & 7 \\
29 & Sengon Laut & Albizia falcate & 1 \\
30 & Sukun & Artocarpus altilis & 5 \\
31 & Waru & Hibiscus macrophyllus & 7204 \\
\hline & & Total individu & \\
\hline
\end{tabular}

Sumber : Data primer (2019).

Spesies vegetasi yang ditemukan di hutan rakyat ini mencapai 31 jenis dengan total 1.204 individu yang tersebar pada 15 klaster plot. Vegetasi dengan jumlah paling banyak yang ditemukan pada plot pengamatan adalah tanaman Kakao yang mencapai 356 individu dan menjadi tanaman utama para petani sehingga menyebabkan jumlah tanaman kehutanan dan Multi Purpose Tree Species (MPTS) cenderung rendah. Menurut Nurdina et al (2015), tanaman pada lahan agroforestri banyak didominasi oleh kakao. Sehingga tidak mengherankan jika masyarakat lebih memprioritaskan tanaman kakao dibandingkan dengan tanaman kehutanan dan MPTS pada lahannya.

\section{Simpanan Karbon Hutan Rakyat Kelurahan Pinang Jaya}

Nilai simpanan karbon pada 15 klaster plot disajikan pada Gambar 3. Klaster plot yang memiliki simpanan karbon terbesar adalah klaster plot 13 yakni sebesar 83,64 tC/ha. 


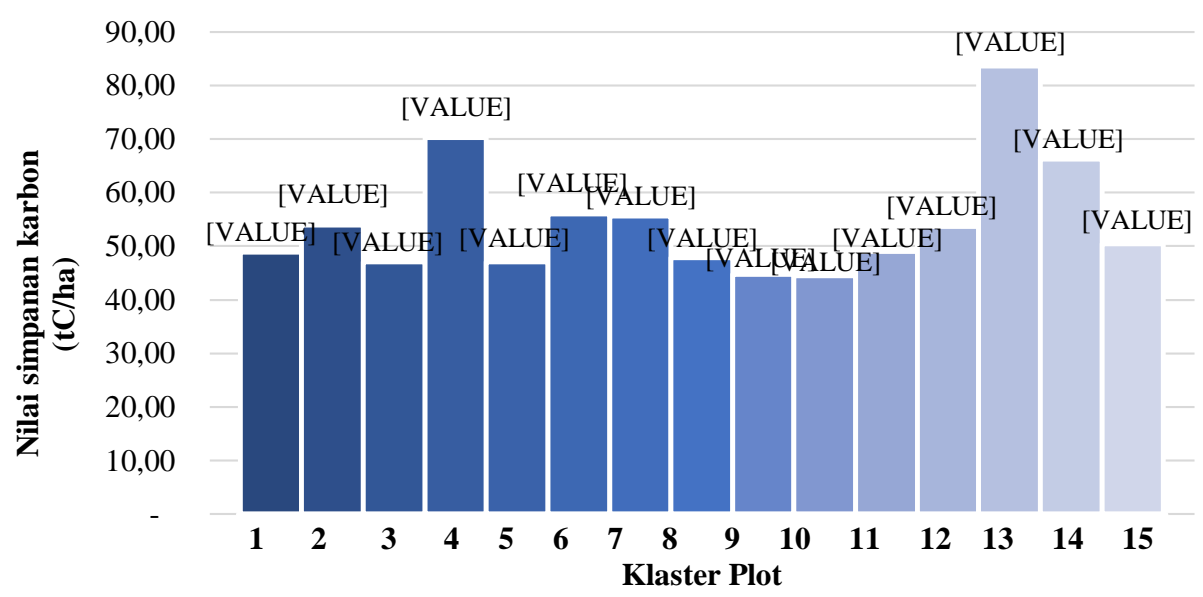

Gambar 3. Simpanan karbon pada 15 klaster plot

Figure 3. Carbon stock of 15 cluster plot

Klaster plot 13 menjadi plot dengan simpanan karbon terbesar karena jumlah dan jenis tanaman yang ada di klaster plot tersebut lebih banyak dibandingkan klaster plot lainnya. Jumlah tanaman yang ada di klaster plot 13 yakni 93 individu yang terdiri dari 11 jenis tanaman yaitu Cengkeh, Durian, Jati, Kakao, Karet, Kelapa, Mahoni, Mangga, Melinjo, Petai, dan Randu. Namun jumlah individu terbesar bukan pada klaster plot 13, tetapi pada klaster plot 12 dan hal ini terjadi disebabkan oleh sejumlah tanaman kakao yang ada di CL 13 mengalami kematian (nekromasa) dan dibersihkan oleh petani sehingga menyebabkan jumlah tanaman pada CL 13 tidak sebanyak pada CL 12. Hubungan antara besar simpanan karbon dengan jumlah individu pada 15 klaster plot terdapat pada Gambar 4.

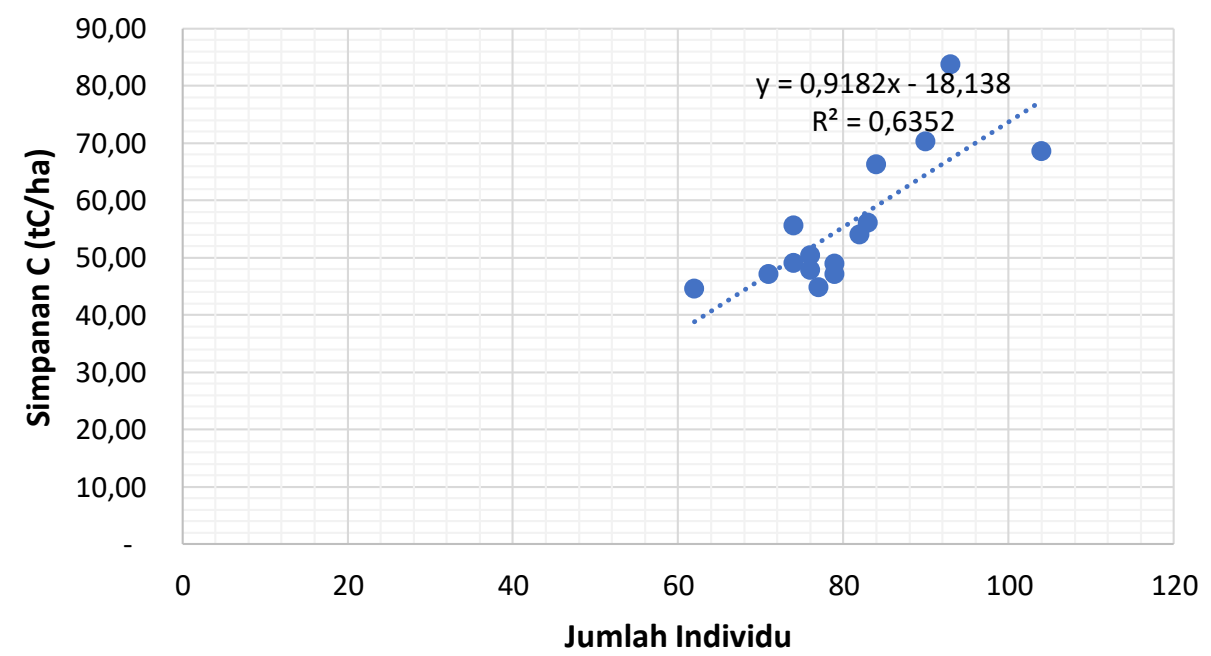

Gambar 4. Hubungan antara simpanan karbon dengan jumlah individu Figure 4. Correlation between carbon storage and number individuals 
Berdasarkan Gambar 4 dengan bentuk garis yang linear pada grafiknya mengindikasikan bahwa jumlah individu berperan dalam mempengaruhi besar simpanan karbon. Semakin banyak jumlah individu pada klaster plot maka akan memperbesar nilai simpanan karbonnya, juga sebaliknya semakin sedikit jumlah individu maka nilai simpanan karbonnya juga semakin rendah.

Klaster plot yang memiliki simpanan karbon terkecil yakni klaster plot 10, sebesar 44,49 tC/ha dan terdiri dari 62 individu. Klaster plot 10 merupakan klaster plot dengan jumlah individu paling rendah dibandingkan dengan klaster plot lainnya. Meskipun jenis tanaman yang ada di klaster plot 10 ini mencapai 17 jenis, namun jumlahnya tidak sebanding dengan klaster plot lain. Klaster plot lain selain klaster plot 10 dan 13 memiliki nilai yang terletak di antara keduanya. Jumlah tanaman terbanyak yakni terletak di klaster plot 12 sebanyak 104 individu. Dominasi terbesar oleh Kakao menyebabkan nilai simpanan karbon pada klaster plot 12 cenderung lebih rendah dibandingkan dengan klaster plot lain yang dominasi tanaman kehutanan dan MPTSnya lebih banyak, seperti pada klaster plot 13.

\section{Analisis Karbon Tersimpan Hutan Rakyat Kelurahan Pinang Jaya}

Data perbandingan besar simpanan karbon yang terdiri dari AGB, nekromasa, serasah dan tumbuhan bawah pada masing-masing gudang karbon ditunjukkan pada Tabel 2.

Tabel 2. Perbandingan fraksi karbon pada masing-masing gudang karbon Table 2. Comparison of carbon fraction for each carbon pool

\begin{tabular}{ccccccccc}
\hline $\begin{array}{c}\text { Cluster } \\
\text { plot }\end{array}$ & \multicolumn{2}{c}{$\begin{array}{c}\text { Biomasa di atas } \\
\text { tanah (AGB) }\end{array}$} & \multicolumn{2}{c}{ Nekromasa } & \multicolumn{3}{c}{$\begin{array}{c}\text { Serasah dan } \\
\text { Tumbuhan } \\
\text { Bawah }\end{array}$} \\
\cline { 2 - 9 } & tC/ha & $\%$ & tC/ha & $\%$ & tC/ha & $\%$ & tC/ha & $\%$ \\
\hline 1 & 42,14 & 86,27 & 6,68 & 13,67 & 0,029 & 0,06 & 48,85 & 100,00 \\
2 & 50,13 & 92,83 & 3,85 & 7,12 & 0,029 & 0,05 & 54,00 & 100,00 \\
3 & 45,61 & 96,92 & 1,42 & 3,01 & 0,034 & 0,07 & 47,06 & 100,00 \\
4 & 64,84 & 92,32 & 5,36 & 7,63 & 0,032 & 0,05 & 70,23 & 100,00 \\
5 & 43,98 & 93,42 & 3,07 & 6,52 & 0,031 & 0,07 & 47,08 & 100,00 \\
6 & 53,67 & 95,79 & 2,32 & 4,15 & 0,034 & 0,06 & 56,03 & 100,00 \\
7 & 55,18 & 99,25 & 0,39 & 0,71 & 0,022 & 0,04 & 55,59 & 100,00 \\
8 & 46,84 & 97,99 & 0,94 & 1,97 & 0,022 & 0,05 & 47,80 & 100,00 \\
9 & 43,12 & 96,40 & 1,58 & 3,52 & 0,036 & 0,08 & 44,73 & 100,00 \\
10 & 42,74 & 96,08 & 1,72 & 3,87 & 0,021 & 0,05 & 44,49 & 100,00 \\
11 & 47,97 & 97,75 & 1,07 & 2,18 & 0,035 & 0,07 & 49,07 & 100,00 \\
12 & 50,08 & 93,33 & 3,54 & 6,60 & 0,037 & 0,07 & 53,66 & 100,00 \\
13 & 83,12 & 99,37 & 0,51 & 0,61 & 0,021 & 0,02 & 83,64 & 100,00 \\
14 & 65,95 & 99,54 & 0,28 & 0,42 & 0,025 & 0,04 & 66,25 & 100,00 \\
15 & 48,43 & 96,06 & 1,95 & 3,87 & 0,038 & 0,07 & 50,41 & 100,00 \\
\hline Rata- & 52,25 & 95,71 & 2,31 & 4,23 & 0,03 & 0,05 & 54,59 & 100,00 \\
rata & 52,25 & & & & & & &
\end{tabular}

Nilai rata-rata simpanan karbon seluruh gudang karbon pada 15 klaster plot yakni sebesar 54,59 tC/ha. Nilai AGB menjadi penyumbang simpanan karbon dengan persentase terbesar yaitu 95,71\%, dengan rata-rata simpanan karbonnya sebesar 52,25 tC/ha. Proporsi penyimpan karbon terbesar di suatu lahan ditemukan yakni pada tegakan pohon (Hairiah dan 
Rahayu, 2007) dan serapan karbon sangat dipengaruhi oleh biomassa (Natalia et al., 2014). Hal ini menandakan bahwa pohon menjadi sumbangsih terbesar dalam penyimpan karbon hutan. Penelitian lain mendukung pernyataan ini seperti Yuniawati et al., (2011) menyatakan bahwa karbon yang tersimpan pada tanaman diperoleh dari hasil fotosintesis. Yamani (2013) juga menyatakan bahwa batang merupakan bagian pohon berkayu sebagai tempat penyimpanan hasil dari fotosintesis, sehingga umumnya memegang peranan besar dalam penyimpanan karbon. Putri dan Wulandari (2015) juga melaporkan bahwa pohon dengan diameter besar dapat menyimpan lebih banyak karbon karena kontribusi utama biomasa yaitu pada batang.

Nekromasa menjadi penyumbang simpanan karbon dengan persentase terbesar kedua setelah AGB, yaitu sebesar 4,23\%, dengan rata-rata sebesar 2,31 tC/ha. Nilai estimasi simpanan karbon yang bersumber dari nekromasa pada hutan rakyat ini tergolong lebih tinggi jika dibandingkan dengan hutan rakyat lain, misalnya Ristiara (2016) yang melaporkan bahwa nekromasa menyumbang 0,81 tC/ha di hutan rakyat Kabupaten Tanggamus.

Serasah dan tumbuhan bawah digabungkan menjadi satu gudang karbon dan memiliki sumbangsih sebesar $0,05 \%$ untuk seluruh total simpanan karbon pada 15 klaster plot dengan nilai rata-rata sebesar 0,03 tC/ha. Menurut Ristiara et al.,(2017), secara umum, tumbuhan bawah hanya menyimpan karbon dalam jumlah yang sedikit dan biasanya kandungan karbon serasah tidak lebih besar dari kandungan karbon nekromasa.

\section{Penetapan Kategori Kesehatan Hutan pada Hutan Rakyat Kelurahan Pinang Jaya}

Nilai ambang batas volume karbon digunakan untuk menentukan kategori kesehatan hutan di Hutan Rakyat Kelurahan Pinang Jaya. Berdasarkan nilai tertinggi dan terendah dari hasil perhitungan volume karbon pada semua klaster plot, nilai ambang batas kesehatan Hutan Rakyat Kelurahan Pinang Jaya tersaji pada Tabel 3.

Tabel 3. Nilai ambang batas kesehatan hutan di hutan rakyat Kelurahan Pinang Jaya Table 3. The health threshold value of community forest at Pinang Jaya Village

\begin{tabular}{cc}
\hline Nilai Ambang & Kategori Kesehatan Hutan \\
\hline $44,49-57,54$ & Buruk \\
$57,55-70,60$ & Sedang \\
$70,61-83,66$ & Baik \\
\hline
\end{tabular}

Sumber : Data primer (2019).

Nilai ambang batas mengelompokan data menjadi 3 (tiga) kategori kesehatan hutan yaitu Buruk, Sedang, dan Baik. Pengkelasan kesehatan hutan ini bersifat relatif sehingga sifatnya mungkin akan berbeda dengan penelitian lainnya. Hal ini karena pengkelasan yang dilakukan yaitu berdasarkan interval populasi sampel penelitian sehingga dengan kondisi data karbon antara hutan/penggunaan lahan yang satu dengan lainnya yang berbeda, akan mempengaruhi nilai interval kelas pada setiap penelitian. Seperti pada penelitian Lestari et al. (2019), yang dilakukan di Hutan Lindung Register 25 Provinsi Lampung, menunjukan bahwa niiai ambang batasnya yaitu 209,97 - 721,35 untuk kategori Buruk, 721,36 - 1.232,74 untuk kategori Sedang, dan 1.232,75 - 1.744,13 untuk kategori Baik.

Setelah didapatkan nilai ambang batas untuk kesehatan hutan pada hutan rakyat Keluran Pinang Jaya yang terdapat pada Tabel 3, didapatkanlah kategori pada ke-15 klaster plot yang terdapat pada Tabel 4. 
Tabel 4. Kategori pada masing-masing klaster plot Table 4. Category of each plot cluster

\begin{tabular}{ccc}
\hline Cluster plot/CL & $\mathrm{tC} /$ ha & Kategori (Buruk/Sedang/Baik) \\
\hline CL1 & 48,85 & Buruk \\
CL2 & 54,00 & Buruk \\
CL3 & 47,06 & Buruk \\
CL4 & 70,23 & Sedang \\
CL5 & 47,08 & Buruk \\
CL6 & 56,03 & Buruk \\
CL7 & 55,59 & Buruk \\
CL8 & 47,80 & Buruk \\
CL9 & 44,73 & Buruk \\
CL10 & 44,49 & Buruk \\
CL11 & 49,07 & Buruk \\
CL12 & 53,66 & Buruk \\
CL13 & 83,64 & Baik \\
CL14 & 66,25 & Sedang \\
CL15 & 50,41 & Buruk \\
\hline Rata-rata & 54,59 & Buruk \\
\hline
\end{tabular}

Jumlah klaster plot dengan kategori Baik hanya terdapat 1 buah, yaitu pada klaster plot 13 dengan nilai simpanan karbonnya yaitu 83,64 tC/ha, kemudian untuk kategori Sedang terdapat pada klaster plot 4 dan 14 dengan masing-masing nilai simpanan karbonnya 70,23 tC/ha dan 66,25 tC/ha, sedangkan pada 12 klaster plot lainnya yaitu klaster plot 1-3, 5-12, dan 15 termasuk ke dalam kategori Buruk karena nilai simpanan karbonnya di bawah nilai ambang 57,55. Persentase ketiga kategori terdapat pada Gambar 5.

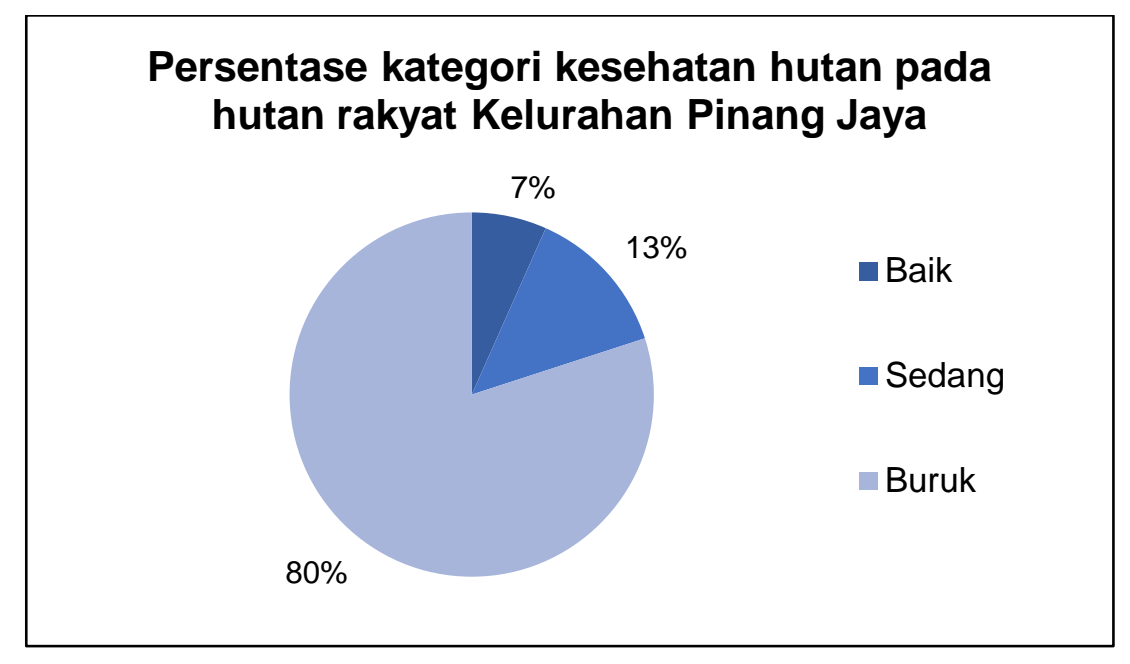

Grafik pada Gambar 5 menunjukkan bahwa persentase kesehatan hutan pada Hutan Rakyat Kelurahan Pinang Jaya adalah 7\% kategori Baik, 13\% kategori Sedang, dan 80\% kategori Buruk. Hal ini menggambarkan bahwa kondisi kesehatan hutan pada hutan rakyat Kelurahan Pinang Jaya didominasi oleh ketegori Buruk (80\%), sehingga perlu untuk dilakukan penyebaran informasi terkait hasil penelitian ini terhadap petani dengan harapan petani dapat 
menambah jumlah tanaman kehutanan dan MPTS di lahan miliknya sehingga berdampak positif dalam meningkatkan simpanan karbon dan memperbaiki kesehatan hutan pada hutan rakyat tersebut.

\section{KESIMPULAN dan SARAN}

Dalam penelitian ini mayoritas hutan rakyat di Keluran Pinang Jaya (80\%) memiliki status kesehatan hutan yang termasuk kategori Buruk. Kategori lain yaitu Baik dan Sedang berturut-turut yakni $7 \%$ dan 13\%. Hasil ini dapat memberi indikasi bahwa simpanan karbon dapat digunakan sebagai indikator kesehatan hutan pada hutan rakyat dan harapannya penelitian mengenai simpanan karbon hutan sebagai salah satu indikator kesehatan hutan dapat dilakukan pada jenis hutan lainnya. Penyebaran informasi terkait hasil penelitian penting dilakukan dan menjadi langkah awal agar para petani mengetahui kondisi hutan rakyat mereka sehingga harapannya dapat memperbaiki pengelolaan dengan menambah tanaman kehutanan dan MPTS di lahan mereka.

\section{DAFTAR PUSTAKA}

Brown, S. (1997). Estimating Biomass And Biomass Change Of Tropical Forest A Primer. USA : FAO. Forestry Paper 134.

[BSN] Badan Standarisasi Nasional. (2011). Pengukuran \& Perhitungan Cadangan Karbon. Pengukuran Lapangan untuk Penaksiran Cadangan Karbon Hutan (Ground Based Forest Carbon Accounting). Jakarta: Badan Standarisasi Nasional.

Chave, J.. Andalo, S. Brown, M. A. Cairns, J Q Chambers, D. Eamus, H Folster, F Fromard, N Higuchi, T Kira, J-P Lescure, B W Nelson, H. Ogawa, H. Puig, B. Riera, T. Yamakura. (2005). Tree allometry and improved estimation ofand balance in tropical forests. Jurnal Oecologia, 145, 87-99.

Departemen Kehutanan. (2013). Bab II : Inventarisasi Hutan. Artikel. http://www. dephut.go.id/Halaman/pranalogikehutanan/ bab2.pdf. Diakses pada 26 September 2019.

[EPA] Environmental Protection Agency. (2013). Inventory of U.S. Greenhouse Gas Emissions and Sinks: 1990-2012. Washington DC: EPA.

Djumanta, W., dan Susanti, D. 2008. Belajar Matematika Aktif dan Menyenangkan untuk SMP/MTs Kelas IX. Jakarta: Pusat Perbukuan Departemen Pendidikan Nasional.

Hairiah, K dan Rahayu S. (2007). Pengukuran Karbon Tersimpan di Berbagai Macam Penggunaan Lahan. World Agroforestry Centre ICRAF, SEA Regional Office. Indonesia: University of Brawijaya.

ITTO \& SEAMEO BIOTROP. (2001). Forest Health Monitoring to Monitor the Sustainability of Indonesia Tropical Rain Forest. Volume I, II, III. ITTO.

Lestari, R, N. (2017). Analisis Karbon di Atas Tanah sebagai Indikator Kesehatan Hutan Lindung Register 25. Skripsi. Bandar Lampung: Universitas Lampung.

Lestari, R, N., Wulandari, C., Safe'i, R., dan Darmawan, A. (2019). Analysis of above ground carbon as indicator for forest health in protection forest registers 25. Jurnal Sylva Indonesia, 2(1), 01-10.

Manuri, S., Putra, C.A.S. dan Saputra, A.D. (2011). Teknik Pendugaan Cadangan Karbon Hutan. Merang REDD Pilot Project, German International Cooperation (GIZ). Palembang.

Natalia, D., Yuwono, S.B. \& Qurniati, R. (2014). Potensi penyerapan karbon pada sistem agroforestri di Desa Pesawaran Indah Kecamatan Padang Cermin Kabupaten Pesawaran Provinsi Lampung. Jurnal Sylva Lestari, 2(1), 11-20. 
Nurdina, IF., Kustanti A. dan Hilmanto R. (2015). Motivasi petani dalam mengelola hutan rakyat di Desa Sukoharjo 1 Kecamatan Sukoharjo Kabupaten Pringsewu. Jurnal Sylva Lestari, 3 (3), 51-62.

Putri, A.H.M. dan Wulandari, C. (2015). Potensi penyerapan karbon pada tegakan damar mata kucing (Shorea javanica) di Pekon Gunung Kemala Krui Lampung Barat. Jurnal Sylva Lestari, 3(2), 13-20.

Ristiara, L. (2016). Estimasi Karbon Tersimpan pada Hutan Rakyat di Pekon Kelunggu Kabupaten Tanggamus. Skripsi. Lampung: Universitas Lampung.

Ristiara, L., Hilmanto, R,. Duryat. (2017). Estimasi karbon tersimpan pada hutan rakyat di Pekon Kelungu Kabupaten Tanggamus. Jurnal Sylva Lestari, 5(1), 128-138.

Rizki, G.M., Bintoro, A., dan Hilmanto, R. (2016). Perbandingan emisi karbon dengan karbon tersimpan di hutan rakyat Desa Buana Sakti Kecamatan Batanghari Kabupaten Lampung Timur. Jurnal Sylva Lestari, 4(1), 89-96.

Safe'i, R., Hardjanto, Supriyanto, dan Sundawati, L. (2015). Pengembangan metode penilaian kesehatan hutan rakyat sengon (Falcatania Moluccana). Jurnal Penelitian Hutan Tanaman, 12(3), 175-187.

Suharjo, B. H., dan Wardhana, H. F. P. (2011). Pendugaan potensi simpanan karbon pada tegakan pinus (Pinus merkusii) di KPH Cianjur perum perhutani unit iii Jawa Barat dan Banten. Jurnal Silvikultur Tropika, 03, 96-100.

Umroni, A. (2012). Metode inventarisasi model-model pengelolaan hutan rakyat di NTT. Jurnal Warta Cendana, 6 (1), 12-18.

USDA-FS. (1999). Forest Health Monitoring: Field Methods Guide (International 1999). Asheville NC: USDA Forest Service Research Triangle Park.

Yamani, A. (2013). Studi kandungan karbon pada hutan alam sekunder di hutan pendidikan Mandiangin fakultas kehutanan unlam. Jurnal Hutan Tropis, 1(1), 85-91.

Yuniawati, Budiman, A., dan Elias. (2011). Estimasi potensi biomassa dan massa karbon hutan tanaman Acacia crassicarpa di lahan gambut : studi kasus di areal HTI kayu serat di Pelalawan, Provinsi Riau. Jurnal Penelitian Hasil Hutan,29(4), 343-355. 